Review article

Section: Food Technology

\title{
Technological and Nutritional Challenges, and Novelty in Gluten-Free Breadmaking: a Review
}

\author{
Paola Conte ${ }^{1}$, Costantino Fadda ${ }^{1}$, Natalia Drabinska ${ }^{2}$, Urszula Krupa-Kozak ${ }^{2 *}$ \\ 'Dipartimento di Agraria, Università degli Studi di Sassari, Sassari, Italy; pconte@uniss.it; \\ ${ }^{2}$ Department of Chemistry and Biodynamics of Food, Institute of Animal Reproduction and Food Research \\ of Polish Academy of Sciences, Olsztyn, Poland
}

Key words: gluten-free breadmaking, gluten-related disorders, texture characteristics, nutritional value, sensory properties, review

The presence of gluten is considered fundamental for successful breadmaking. However, the ingestion of gluten by susceptible individuals has been associated with the development of gluten-related disorders such as celiac disease, wheat allergy, and non-celiac gluten sensitivity. The elimination of gluten from cereal-based baked products has a detrimental effect on the breadmaking process and sensory properties, and raises technological challenges in terms of making good quality leavened bread. The use of non-gluten raw materials changes the rheological behaviour of the gluten-free dough, which may result in different processing performance and associated post-baking quality of the obtained bread. Gluten-free bread tends to have a poor visual texture characteristics, a low nutritional value, reduced mouthfeel and flavour, as well as a shorter shelf-life. The aim of this review is to present the main problems related to gluten-free breadmaking technology and to summarise recent findings in the improvement of the technological, nutritional, and sensory properties of gluten-free bread. A great deal of this review focuses on the development of novel and healthy gluten-free breads formulated with flours, starches, hydrocolloids, and alternative nutrient-dense raw materials, which should fulfil all quality requirements for bakery products as well as meet the needs of celiac consumers.

\section{INTRODUCTION}

Bread is considered a staple food worldwide [Simicet et al., 2018; Wandersleben et al., 2018]. Gluten proteins or, specifically, the gliadin fraction of wheat and the prolamins from other cereals such as barley (hordeins) and rye (secalins) are responsible for the viscoelastic properties of the dough and the bread-baking unique asset [Peña-Bautista et al., 2017]. However, for individuals who suffer from celiac disease (CD) or other gluten-related disorders (such as wheat allergy (WA) and non-celiac gluten sensitivity (NCGS)) even the ingestion of a small amount of gluten can lead to deleterious and serious health risks [Scherf et al., 2016; Bathrellou et al., 2018], which are graphically depicted in Figure 1. A strict and life-long gluten-free diet (GFD) is the only available therapy for patients suffering from $C D$, and research results showed improvements in both symptomatology and small bowel histology [Haines et al., 2008]. Patients with NCGS and WA also benefit from a GFD, although individuals with WA do not need to restrict rye, barley, and oats from their diet [Pietzak, 2012].

In reality, a complete avoidance of gluten intake is very difficult, due to gluten ubiquity in human foods, hidden gluten sources, and food contamination. Due to the on-going need for gluten-free products, the gluten-free market is growing fast. While a strict adherence to GFD may lead to nutrition-

\footnotetext{
* Corresponding Author: Tel.: +48 8952346 18; Fax: +48 895234601

E-mail: u.krupa-kozak@pan.olsztyn.pl (U. Krupa-Kozak)
}

al deficiencies in the longer term, the absence of gluten has a detrimental effect on breadmaking process and raises technological challenges in making good quality leavened bread [Horstmann et al., 2018]. In fact, the technological and sensory characteristics of gluten-free bread (GFB) are worse than those of conventional gluten-containing bread [Primo-Martín et al., 2006]. In general, gluten-free baked products are characterized by a crumbling texture, pale crust colour as well as a faster staling rate [Gallagher et al., 2003]. Considerable efforts have been made to improve GFB quality: nutrient-dense ingredients, additives with gluten-imitating function and diverse technologies have been studied in the hopes of narrowing the gap between gluten-free and gluten-containing bread [Capriles \& Arêas, 2014; Drabińska et al., 2016]. The aim of this review is to provide recent findings in improving the technological, nutritional and sensory properties of GFB.

\section{CONVENTIONAL VS. GLUTEN-FREE BREADMAKING}

Conventional and gluten-free breadmaking are processes that differ substantially in terms of the complexity of formulations used (including main ingredients and amount of water), dough rheological behaviour, and overall quality of the final product [Conte et al., 2016; Morreale et al., 2018a]. In traditional breadmaking, the term "bread" usually refers to a yeast-leavened product or sourdough bread specifically made with wheat flour. The reason why bread is usually made with wheat flour derives from the unique properties of the in- 


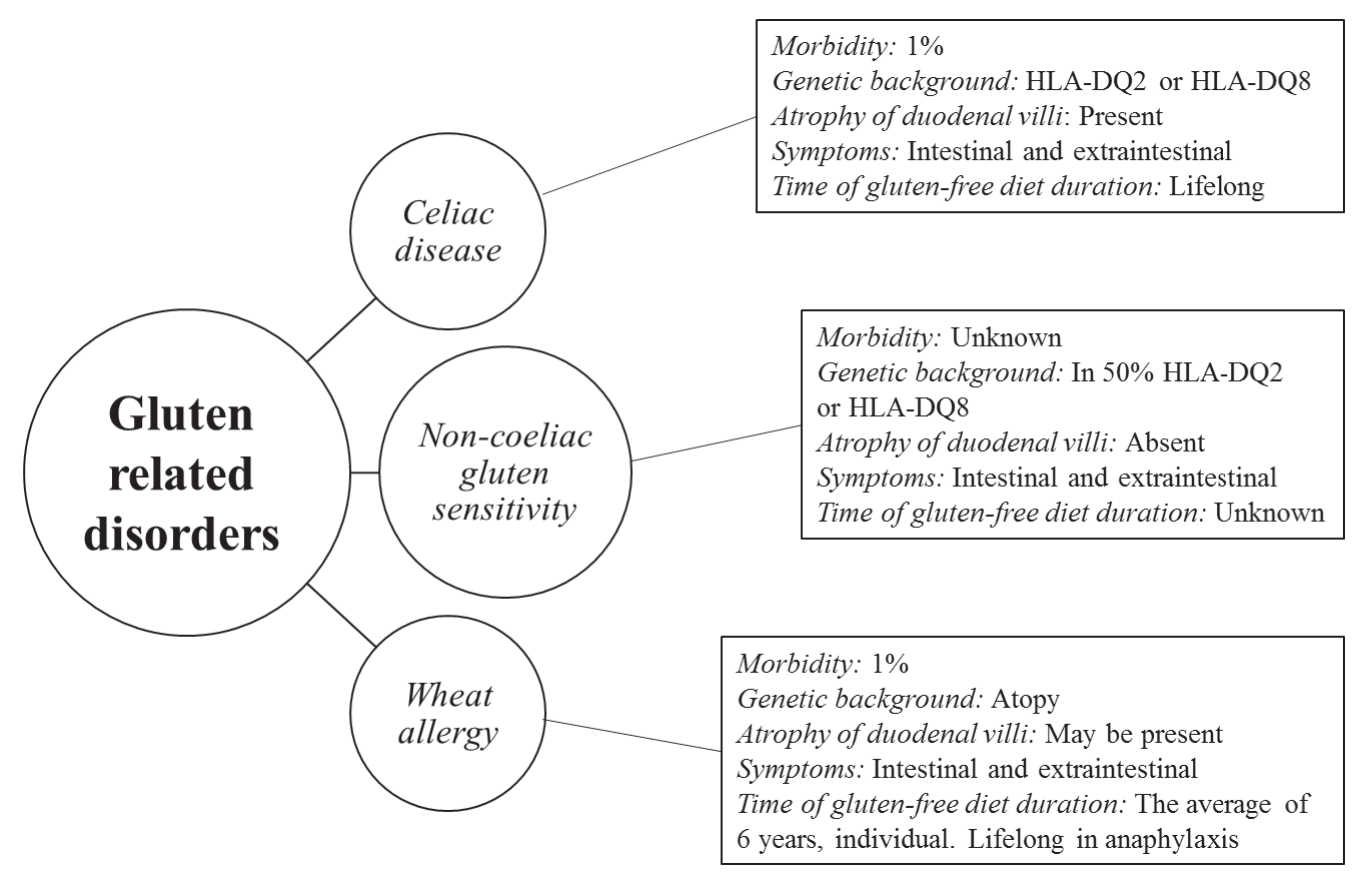

FIGURE 1. Short characteristics of gluten-related disorders.

soluble fraction of wheat protein (gliadin and glutenin) to form, when flour is hydrated and in the presence of mechanical work input, a cohesive viscoelastic mass called a gluten network. Thus, in wheat bread, gluten is considered the main structure-forming complex with an exceptional ability to form a tenacious, extensible, and elastic dough capable of entrapping gas during both proofing and the early stage of baking as well as enclosing starch granules and fibre fragments [Scanlon \& Zghal, 2001; Gallagher et al., 2004]. These characteristics of the dough lead to a final bread with a good loaf volume and a typical crumb structure that results in a sponge-like texture, which is highly desirable in the leavened baked goods.

In gluten-free breadmaking, in which the elimination of gluten becomes a necessity, the absence of this continuous three-dimensional protein-starch matrix significantly affects the rheology of the doughs, the production process, and the overall quality of the final breads [Ronda et al., 2017]. Gluten-free doughs, which cannot develop a network similar to traditional breads due to differences in their protein properties, are less elastic and cohesive, and stickier and more difficult to handle than their gluten-containing counterparts [Ronda et al., 2017]. In order to obtain doughs with acceptable consistency and better behaviour during the mixing phase, gluten-free flours/starches require higher amounts of water than wheat flour does. Thus, gluten-free doughs, which have a viscosity more like that of cake batters, are often called batters instead of doughs. The final products, in turn, tend to show some quality defects such as lower specific volume; lighter crumb and crust colour; rough, dry and crumbly texture; and a shorter shelf life [Gallagher et al., 2004; Houben et al., 2012; Jnawali et al., 2016]. Therefore, the production of GFBs, unlike their wheat-containing counterparts, requires different technological solutions. The development of GFB has generally involved the use of complex formulations consisting of a combination of different ingredients and additives able to imitate the viscoelastic properties of gluten and, consequently, the appearance, quality, and sensory properties of the bread-like products. To this end, due to their negligible structure-building capability, the most common flours and/or starches from different origins (such as rice, corn, potato, and cassava) usually included in GFB formulations, were often combined with binding agents, such as hydrocolloids and protein [Capriles \& Arêas, 2014]. Certainly, the most suitable basic ingredient for GFB preparation is rice (Oryza sativa) flour. This is probably due to its neutral flavour, white colour, hypoallergenic properties, high amount of easily digested carbohydrates, and its low sodium content [Rosell $\&$ Marco, 2008]. However, the use of rice flour in gluten-free breadmaking is also associated with some technological disadvantages. In fact, due to the poor functional properties of its proteins and the low level of prolamins, it is unable to form viscoelastic doughs required to retain the carbon dioxide produced during proofing, leading to a product with low specific volume and a compact crumb [Rosell \& Marco, 2008]. However, despite some discrepancies reported in the literature, it seems that not all varieties of rice and their related amylose contents influence the quality of GFB in the same way [Cornejo \& Rosell, 2015]. As reported by Kadan et al. [2001], the partial replacement (10\%) of a long-grain rice variety with a short grain rice resulted in breads with softer crumb and slower retrogradation than those produced with $100 \%$ long-grain rice. de la Hera et al. [2013] obtained short-grain GFB with higher specific volume and lower hardness values than those of breads made of long rice varieties. On the contrary, Cornejo \& Rosell [2015] analysing the breadmaking potential of six long-grain rice varieties, obtained GFBs with characteristics similar to those previously reported for breads made of short-grain varieties. They concluded that the breadmaking properties of rice flour might be more affected by the synergic effect of other factors (particle size, 
protein conformation, starch structure) than by the length of the rice grain. Apart from rice flour, corn meal (Zea mays) is the second basic ingredient most often used in gluten-free products. In particular, the yellow corn varieties, due to their characteristic yellow colour and distinctive flavour, are more suitable to produce pasta, whereas, the white maize varieties are the flour/starch sources most often used in gluten-free breadmaking [Hager et al., 2012].

Not only starch-containing flours, but also starches from different origins are the main players in providing structure and texture of the manufactured breads [Jnawali et al., 2016]. During the bread baking process, starch is able to bind water and form a gas-permeable structure influencing, in turn, water retention and dough rheology [Houben et al., 2012; Witczak et al., 2016]. In fact, starch granules gelatinize (trough granules swelling and partial solubilisation of starch) and form a starch paste able to trap air bubbles [Zannini et al., 2012]. As a result, the addition of starch in GFB formulae (either as a single starch or a composite starch mixture) leads to a product with a higher volume, and a softer, more cohesive and compact crumb structure [Gómez \& Sciarini, 2015]. However, it is worth highlighting that not all kinds of starches behave in the same way, as their functional characteristics depend on their origin, particle size, amylose/ amylopectin content, water swelling and solubility, pasting and gelling, starch treatment, and interaction with other ingredients [Witczak et al., 2016; Zhang et al., 2017]. However, during food processing, despite the numerous advantages of starch, its native forms show a limited resistance to physical conditions, such as high tendency to retrogradation and syneresis, loss of viscosity (especially at low $\mathrm{pH}$ conditions), low thermal stability, and inappropriate rheological characteristics of pastes and gels. For this reason, modifications of starches by chemical reactions or physical methods have been proposed to overcome some of these shortcomings [Witczak et al., 2012; Yousif et al., 2012]. Korus et al. [2009] observed that the partial replacement of corn starch with increasing percentages of tapioca and corn resistant starch preparations led to gluten-free doughs with increased elastic behaviour (increase of both storage and loss moduli, and $\mathrm{G}^{\prime}$ $\left.>\mathrm{G}^{\prime \prime}\right)$ and rheological properties typical of a week gel $(\tan \delta$ $>0.1$ ). The resulting GFBs showed diminished crumb hardness values with the increasing amounts of resistant starch preparations applied. These authors also found that the addition of resistant starch raised total dietary fibre, by up to $89 \%$, as compared to the control samples.

The relatively poor functional properties of the above-mentioned basic ingredients, as well as the necessity to mimic the functionalities of gluten, and the inclusion of other polymeric substances such as hydrocolloids and non-gluten protein, are critical factors in a starch-based system like GFB. Hydrocolloids, also known as food gums, are substances consisting of hydrophilic, long-chain, high molecular weight molecules, including different polysaccharides but also some proteins, such as gelatin [Hoefler, 2004]. When they are incorporated in a water-based system, they exhibit a range of functions, including the primary gelling and thickening, but also emulsifying and encapsulating ones [Hoefler, 2004]. Moreover, the hydrocolloids classified as soluble fibres serve important physiological functions [Matos \& Rosell, 2015]. The addition of hydrocolloids to GFB formulae could have several effects on both intermediate and end products. (a) At the dough level, due to their ability to act as water binders, they raise the viscosity of the system, improve the viscoelastic properties of the dough and increase, in turn, its gas-holding capacity. Furthermore, they affect swelling and gelatinization of the starch granules. (b) At the bread level, due to their ability to reduce moisture loss, they slow down starch retrogradation and extend the shelf life of the products, preserving their overall quality over time. Additionally, they influence other bread quality attributes, such as specific volume, crumb structure, texture, and sensory properties [Lazaridou et al., 2007; Jnawali et al., 2016]. Different types of hydrocolloids of both natural (agar-agar, carrageen, pectin and $\beta$-glucan, gum arabic, locust bean gum, guar gum and psyllium fibre) and synthetic origin (synthesized cellulose derivatives: hydroxypropylmethyl cellulose (HPMC), carboxymethyl cellulose (CMC), and methyl cellulose (MC); microbial biosynthetic: xanthan gum) have been proposed as gluten replacers in GFBs [Lazaridou et al., 2007; Schober et al., 2008; Demirkesen et al., 2014; Mohammadi et al., 2014; Naji-Tabasi \& Mohebbi, 2014]. However, not all kinds of hydrocolloids behave in the same way. In fact, their interaction with other food polymers, such as starch and protein included in the formulation, the specific hydrocolloid used and its supplementation level (usually up to 2\%), as well as the parameter of the process, could change the type and extent of influence exerted on both dough and bread properties [Lazaridou et al., 2007; Rosell \& Marco, 2008; Capriles \& Arêas, 2014; Jnawali et al., 2016].

\section{GLUTEN-FREE BATTER/DOUGH CHARACTERISTICS}

The quality of GFBs is greatly influenced by the selection and combination of structural ingredients (mainly polysaccharides) that are able to provide stability to the system (by increasing viscosity), as well as prevent an excessive weakening of the protein/starch/hydrocolloids coherent matrix [Scanlon $\&$ Zghal, 2001]. For this reason, in the gluten-free breadmaking process, the development of processable doughs able to stretch in response to the expansion of gases released during fermentation, as well as the formation of dough films able to stretch without rupturing and with sufficient strength to prevent the collapse of the structure, are crucial prerequisites to obtain high quality yeast-leavened products [Singh \& MacRitchie, 2001; Mir et al., 2016]. From a rheological point of view, due to the large amount of water usually added in the complex recipes and also the absence of gluten, gluten-free doughs resemble a semiliquid system which greatly varies in terms of consistency, viscoelasticity, and structural networking [Gallagher et al., 2003; Hager et al., 2012]. Findings from selected recent research related to the rheological properties of dough and bread are summarized in Table 1. Różyło et al. [2015] demonstrated that, depending on the type of flour used (corn, rice, and buckwheat flour), the addition of different amounts of water (from $80 \%$ to $120 \%$ ) to the dough can affect the quality parameters (such as specific volume and crumb hardness) of different types of GFBs. In particu- 
TABLE 1. Different types of flour/starch and amount of water used in gluten-free breadmaking.

\begin{tabular}{|c|c|c|c|c|}
\hline Basic ingredients & Amount of water & Dough properties & Bread properties & References \\
\hline $\begin{array}{l}\text { Corn flour } \\
\text { Corn starch } \\
\text { Potato starch } \\
\text { Rice flour } \\
\text { Buckwheat flour }\end{array}$ & $90 \%, 102 \%$ & $\begin{array}{l}\text { Dough yield } \\
\text { Rheological properties } \\
\text { (Rheometer) } \\
\text { Leavening properties } \\
\text { (Rheofermentometer) }\end{array}$ & $\begin{array}{c}\text { Baking yield } \\
\text { Specific volume } \\
\text { Sensory evaluation }\end{array}$ & [Pruska-Kędzior et al., 2008] \\
\hline $\begin{array}{l}\text { Rice flour } \\
\text { Oat flour } \\
\text { Quinoa flour } \\
\text { Sorghum flour } \\
\text { Teff flour } \\
\text { Buckwheat flour }\end{array}$ & $\begin{array}{l}120 \% \\
95 \% \\
90 \% \\
90 \% \\
90 \% \\
85 \% \\
\end{array}$ & $\begin{array}{l}\text { Microstructural properties } \\
\text { Leavening properties } \\
\text { (Rheofermentometer) }\end{array}$ & $\begin{array}{c}\text { Bake loss } \\
\text { Specific volume } \\
\text { Crumb texture } \\
\text { Crumb structure } \\
\text { Shelf-life } \\
\text { Sensory evaluation }\end{array}$ & [Hager et al., 2012] \\
\hline $\begin{array}{l}\text { Short-grain rice flour } \\
\text { Long-grain rice flour }\end{array}$ & $\begin{array}{c}80 \% \\
110 \%\end{array}$ & $\begin{array}{c}\text { Microstructural properties } \\
\text { Leavening properties } \\
\text { (Rheofermentometer) }\end{array}$ & $\begin{array}{c}\text { Weight loss } \\
\text { Specific volume } \\
\text { Crumb texture }\end{array}$ & [de la Hera et al., 2013] \\
\hline $\begin{array}{l}\text { Corn starch } \\
\text { Rice starch } \\
\text { Rice flour }\end{array}$ & $\begin{array}{c}44.4 \%, 44.7 \% \\
\text { and } 52.7 \%\end{array}$ & $\begin{array}{c}\text { Mixing properties } \\
\text { (Farinograph, Water absorption) } \\
\text { Leavening properties } \\
\text { (Rheofermentometer, Image anlaysis) }\end{array}$ & $\begin{array}{l}\text { Specific volume } \\
\text { Crumb structure } \\
\text { Colour }\end{array}$ & [Cappa et al., 2013] \\
\hline $\begin{array}{l}\text { Rice flour } \\
\text { Corn flour } \\
\text { Corn starch } \\
\text { Quinoa flour }\end{array}$ & $80 \%$ & & $\begin{array}{l}\text { Specific volume } \\
\text { Crumb texture } \\
\text { Sensory evaluation }\end{array}$ & [Elgeti et al., 2014] \\
\hline Rice flour & $150 \%$ & $\begin{array}{l}\text { Rheological properties } \\
\text { (Rheometer) }\end{array}$ & $\begin{array}{l}\text { Specific volume } \\
\text { Hardness } \\
\text { Sensory evaluation } \\
\end{array}$ & [Demirkesen et al., 2014] \\
\hline Rice flour & $70-110 \%$ & & $\begin{array}{c}\text { Weight loss } \\
\text { Specific volume } \\
\text { Crumb texture } \\
\text { Starch digestibility } \\
\text { and glycaemic index } \\
\end{array}$ & [de la Hera et al., 2014] \\
\hline $\begin{array}{l}\text { Corn flour } \\
\text { Rice flour } \\
\text { Buckwheat flour }\end{array}$ & $80-120 \%$ & & $\begin{array}{c}\text { Specific volume } \\
\text { Hardness } \\
\text { Crumb structure } \\
\text { Sensory evaluation } \\
\end{array}$ & [Różyło et al., 2015] \\
\hline Rice flour & $90-110 \%$ & $\begin{array}{c}\text { Rheological properties } \\
\text { (Rheometer) }\end{array}$ & $\begin{array}{c}\text { Specific volume } \\
\text { Hardness }\end{array}$ & [Mancebo et al., 2015] \\
\hline Rice flour & $78-141 \%$ & $\begin{array}{l}\text { Dough extrusion } \\
\text { (Texture Analyzer) } \\
\text { Rheological properties } \\
\text { (Rheometer) }\end{array}$ & $\begin{array}{c}\text { Weight loss } \\
\text { Crumb texture } \\
\text { Crumb structure } \\
\text { Colour } \\
\text { Shelf-life } \\
\end{array}$ & [Ronda et al., 2015] \\
\hline Long grain rice flour & $110 \%$ & & $\begin{array}{l}\text { Specific volume } \\
\text { Crumb texture } \\
\text { Crumb colour }\end{array}$ & [Cornejo \& Rosell, 2015] \\
\hline $\begin{array}{l}\text { Rice flour } \\
\text { Potato starch } \\
\text { Quinoa flour } \\
\text { Buckwheat flour }\end{array}$ & $87 \%$ & $\begin{array}{l}\text { Rheological properties } \\
\text { (Rheometer) }\end{array}$ & $\begin{array}{c}\text { Bake loss } \\
\text { Crumb texture } \\
\text { Crumb microstructural } \\
\text { properties } \\
\text { Colour } \\
\text { Sensory evaluation }\end{array}$ & [Turkut et al., 2016] \\
\hline $\begin{array}{l}\text { Maize flour } \\
\text { Rice flour } \\
\text { Maize starch } \\
\text { Wheat starch } \\
\text { Potato starch } \\
\end{array}$ & $100 \%$ & $\begin{array}{l}\text { Microstructural properties } \\
\text { Rheological properties } \\
\text { (Rheometer) }\end{array}$ & $\begin{array}{c}\text { Crumb microstructural } \\
\text { properties } \\
\text { Specific volume } \\
\text { Crumb texture }\end{array}$ & [Martínez \& Gómez, 2017] \\
\hline White rice flour & $90-110 \%$ & $\begin{array}{l}\text { Rheological properties } \\
\text { (Mixolab®) }\end{array}$ & $\begin{array}{l}\text { Specific volume } \\
\text { Crumb texture } \\
\text { Crumb structure } \\
\text { Colour } \\
\end{array}$ & [Morreale et al., 2018b] \\
\hline
\end{tabular}

lar, they observed that GFBs made with corn flour required the largest amount of water (120\%), while, those made with rice flour required the lowest $(80 \%)$. The importance of hydration levels in determining the viscoelastic behaviour of gluten-free dough/batter and influencing the rheological characteristics of the resulting bread was also recently confirmed by Morreale et al. [2018b]. In the same study, besides the dough hydration levels, the authors underlined the role 


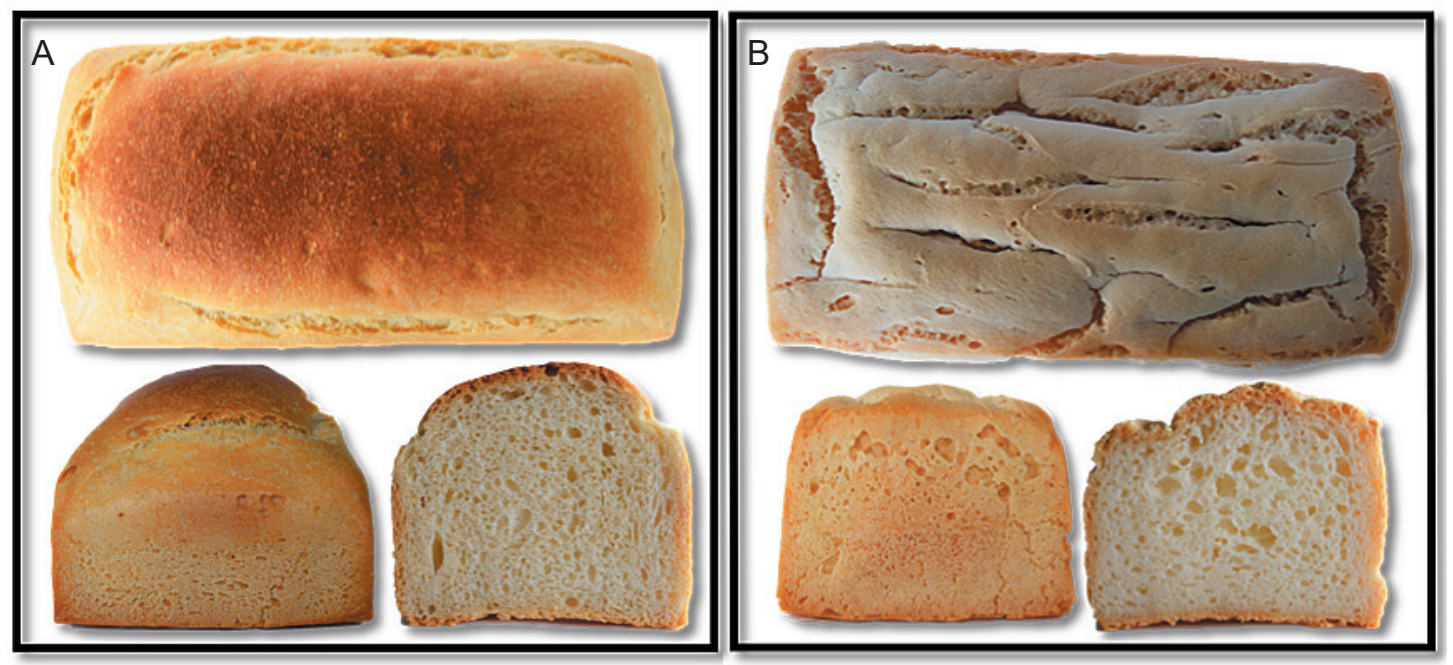

FIGURE 2. Visual appearance of gluten-containing (A) and gluten-free bread (B).

of viscosity $(100,4000$, and 15,000 $\mathrm{mPa} \times \mathrm{s})$ and levels of inclusion $(1,2,3 \%)$ of the hydrocolloid HPMC to improve both batter consistency and some technological parameters of the final products (crumb hardness, cohesiveness, and resilience). The feasibility of improving the rheological properties of gluten-free doughs through the use of different types of hydrocolloids and amounts of water was also explored by many other authors [Cappa et al., 2013; Mancebo et al., 2015; Ronda et al., 2015]. As reported by Pruska-Kędzior et al. [2008], the distinct rheological behaviour of gluten-free doughs may also be due to differences in the endogenous protein content and the fractional compositions of the basic ingredients included in the formulation (maize starch and flour, potato starch, rice flour and buckwheat flour). According to the authors, a complex approach involving rheological and fermentographic methods in future studies on gluten-free dough technology could be useful in the development of GFBs with improved sensory profile and prolonged shelf-life. However, although a number of studies have been conducted to characterize the dough/batter rheological properties using both fundamental and empirical analyses, finding reliable predictors able to correlate gluten-free dough rheological properties with the quality of the resulting breads, still remains an important task [Matos \& Rosell, 2015]. Matos \& Rosell [2013], in an attempt to determine such quality indicators at dough levels, tested seven different gluten-free complex formulations (one based on corn starch, and the other six on rice flour) and evaluated the rheological properties of the dough and the technological and sensory characteristics of the resulting breads. They reported that dough Mixolab parameters showed high correlation coefficients with the physical quality of fresh breads, but relatively low correlations with their sensory characteristics. In particular, a strong relationship was observed between bread crumb hardness and dough consistency during mixing and after cooling. Martínez \& Gómez [2017], using the most common types of flours (rice and maize) and starches (maize, wheat and potato) usually included in gluten-free formulae, studied the mechanistic relations among the development of the starch/flour structure, dough rheology, and bread quality. These authors reported that the structure and morphology of the starch granules and flour particles were the major determinants of dough changes produced during the fermentation and baking phases. The large and compact particles of the flours produced dough with high consistency and breads with volume and textural properties lower than those obtained with starches. In particular, among the starch-based formulations, the small wheat starch granules, which also exhibited the lowest pasting temperature, formed a continuous and uniform starch-hydrocolloid matrix, leading to doughs with a lower consistency but higher holding capacity and, consequently, breads with higher specific volume and better textural properties.

\section{QUALITY OF GLUTEN-FREE BREAD}

\section{Gluten-free bread appearance, texture, and shelf-life}

Despite the considerable advances made in improving gluten-free bakery products, some major problems related to their technological and sensory quality must to be overcome. Due to the need of using non-gluten raw materials, the changes observed in the technological properties of gluten-free doughs may result in different processing performance and associated post-baking quality defects of the resulting breads, which tend to have unattractive appearance, in particular pale crust colour with irregular surface, poor mouthfeel and flavour, and a shorter shelf-life [Houben et al., 2012; Jnawali et al., 2016; Conte et al., 2018]. Visual texture is defined as the appearance of the product, ranging from the crust colour to the loaf volume to the crumb grain structure of each single slice of bread [Wang et al., 2013]. The colour of both crust and crumb is known to be one of the most important visual characteristics, which strongly influence consumer choice [Gallagher et al., 2003; Conte et al., 2018]. GFBs, unlike their wheat-containing counterparts, show unappealing and often too white coloration (Figure 2). It may be due to the natural colour of the conventional raw materials included in the formulations [Gallagher et al., 2003; Różyło et al., 2015]. Furthermore, a small amount of proteins and high water contents hamper the browning reaction, which is the main responsible for the formation of brown pigments [Mohammadi et al., 2014]. 
The specific volume is one of the most important technological parameters of bread quality. However, due to the multiplicity of bread varieties, each of which has its own particular characteristics, the specific volume cannot be considered a quality factor itself. For instance, in the case of breads baked in pans, high values of specific volume, being usually associated with a proper aeration of the bread loaves, are required to obtain products able to satisfy the widest cross-section of consumers. A suitable gas bubble entrapment and a subsequent stabilisation of the foam structure are also fundamental to achieve a fine alveolate structure, in which the resulting pores should be small, regular and spread evenly across the crumb [Elgeti et al., 2014]. It is during baking that the further growth of the gas bubbles previously incorporated during mixing determines dough expansion and, consequently, the final volume and appearance of breads [Scanlon \& Zghal, 2001]. Naji-Tabasi \& Mohebbi [2015] reported that in formulations based on rice flour, corn flour, and corn starch, the addition of cress seed gum and xanthan gum as gluten substitutes led to breads with higher specific volumes and improved cell area fraction. They also reported that hydrocolloids, by forming thick layer, influenced the stability of the gas cells, leading to more regular and solid pores, especially in breads containing cress seed gum. Furthermore, hydrocolloids (by limiting the diffusion of water) had a positive effect on crumb colour during storage.

Apart from visual texture defects, GFBs tend to have high crumb hardness, low cohesiveness and elasticity and, as a consequence, high brittleness with a pronounced tendency to fracture or crumble [Gallagher et al., 2003]. It is well established that such a mechanical behaviour of GFBs, which is usually described by the above-mentioned physical texture parameters, is strongly influenced by product density and porosity. This implies that, in dough processing, all the aspects that change bread volume and cell structure are also major determinants of the bread texture. Demirkesen et al. [2014] studied the effects of the addition of different gums (xanthan, guar, locust bean, agar, MC, CMC, and HPMC) and gum blends (xanthan-guar and xanthan-locust bean) on crumb structure and texture parameters of rice-based GFBs. The authors found that the use of both gum blends and single xanthan, CMC, and HPMC led to breads with homogenous and finer crumb structure in terms of lower porosity and average area of pores, and higher number of pores. They also reported that the hardness, cohesiveness and springiness values were correlated with the internal structure of the crumb. In particular, it was observed that GFBs with softer, more cohesive and elastic crumb, also showed the lower values of porosity, lower average size of pores and higher number of pores. Similarly, de la Hera et al. [2014], studying the impact of dough hydration levels (70, 90, and 110\%) and particle size distribution (fine and coarse) on the quality of rice-based GFBs, found a strong correlation $(r=-0.8931 ; \mathrm{P}<0.001)$ between hardness values and specific volume. In spite of a slightly detrimental effect in the nutritional aspect, better results were obtained with coarse flour and large amounts of water.

Another major disadvantage normally associated with GFBs is the impossibility to keep breads fresh for a longer time. In fact, during storage, baked products undergo a num- ber of physicochemical changes, ranging from the crumb hardening to the loss of crust crispiness and organoleptic freshness to the gradual decrease in consumer acceptance [Fadda et al., 2014]. These alterations are commonly referred to as staling, which is a complex, but not-well understood process that has been associated primarily with moisture redistribution, starch retrogradation, polymers reorganization, and starch-protein interactions [Fadda et al., 2014]. If, on the one hand, the transfer of moisture from the internal to the external region of the loaf is commonly recognized as mainly responsible for the staling of the crust, on the other hand, staling of the crumb is a more complex phenomenon that involves multiple factors [Gray \& Bemiller, 2003]. Certainly, the most widely accepted mechanism involved in the firming of the crumb is the recrystallization of amylopectin. However, also the moisture content and its redistribution among the different constituents of the crumb seems to play a critical role [Gray \& Bemiller, 2003; Ronda et al., 2011]. It should be noted that most GFBs, which are often based on pure starches and require an extra amount of water, are more prone to stale than their gluten-containing counterparts. In fact, owing to the absence of gluten, the transfer of moisture may increase, leading to a product with softer crust and firmer crumb [Gallagher et al., 2003; Sciarini et al., 2010]. In an attempt to delay the staling of GFBs, several authors reported different promising strategies, including: (a) the use of enzymes such as $\alpha$-amylase and cyclodextrin glycosyltransferase, which are able to partially degrade amylopectin, thus hindering its recrystallization, as well as to modify both protein-starch and protein-protein interactions, respectively [Gujral et al., 2003; Haghighat-Kharazi et al., 2018]; (b) the use of some hydrocolloids such as xanthan, CMC, and HPMC, which are able to decrease the loss of moisture content during storage and, consequently, retard both starch retrogradation and crumb hardening [Mohammadi et al., 2014; Mir et al., 2016]; and (c) the use of sourdough technology [Rinaldi et al., 2017].

\section{Nutritional quality of gluten-free bread}

Another concern regarding GFB is related to its nutritional value. Gluten-free cereal-based products, including bread, are mainly made of starches from different sources or refined flours, they lack several macro- and micronutrients and provide smaller amounts of valuable nutrients needed in a healthy and balanced diet [Gallagher et al., 2004; Martin et al., 2013]. Compared to their gluten-containing counterparts, commercial gluten-free products have a lower protein content, inadequate amount of B-group vitamins [Thompson, 1999; Yazynina et al., 2008], and minerals (including iron, zinc, calcium) [Wronkowska et al., 2008; Saturni et al., 2010]. Besides, gluten-free flours are not enriched or fortified like the refined wheat-based flour or products are on a voluntary or mandatory basis [Department of Health, 1998; Akhtar et al., 2011]. Meanwhile, the enrichment of gluten-free flours in minerals and/or vitamins could increase the nutritional status of CD patients and increase the amount of minerals to the level sufficient for prophylactic or therapeutic use.

Nutritional deficiencies are frequently detected in newly diagnosed and untreated CD patients due to chronic inflam- 
mation and malabsorption problem [Wierdsma et al., 2013]. Besides, a GFD which is the only recommended CD treatment may not be nutritionally adequate and well-balanced thus may generate deficiencies that persist in $\mathrm{CD}$ patients following this eliminative diet [Saturni et al., 2010; Penagini et al., 2013]. Iron deficiency anaemia [Theethira et al., 2014] and lower bone mineral density [Meyer et al., 2001; Krupa-Kozak, 2014] were frequently determined in CD patients at time of diagnosis. Hallert et al. [2002] found a poor vitamins status, in particular lower contents of folic acid and vit. B6 in CD patients on a GFD for over 10 years. In turn, Sdepanian et al. [2003] revealed that the mean bone mineral density in adolescents with CD was significantly lower than in the control groups, and that they showed high percentages of magnesium and calcium as well as phosphorous deficiencies.

Recently, a growing number of studies related to gluten-free bakery products besides the focus on the better sensory quality and prolonged shelf-life, pay special attention on the development of products characterised by an improved nutritional quality [Capriles \& Arêas, 2014]. Inclusion of microelements into a GFB formulation is one of the promising methods for the improvement of the nutrition value of GFB without compromising its sensory quality. A GFB enriched in calcium was obtained by Krupa-Kozak et al. [2011a] who evaluated the effect of the individual and combined addition of calcium caseinate and calcium citrate to GFB formulations. Compared with unfortified control GFB, in breads containing calcium citrate alone $(2 \%)$ or containing a mixture of calcium citrate and calcium caseinate $(1.3 \%$ and $0.7 \%$, respectively), a significant increase of calcium levels was determined, which allowed considering the obtained GFBs as good sources of calcium, providing approx. 100-140 mg of calcium per serving. Moreover, the technological and sensory characteristics of calcium-enriched GFBs were favourably modified. In a subsequent study, Krupa-Kozak et al. [2012] assessed the suitability of different organic or inorganic calcium sources (calcium lactate, calcium citrate, calcium chloride, calcium carbonate) in GFB formulations with inulin. The best results were achieved with the addition of calcium carbonate, which additionally raised the overall consumer acceptability of GFB. Kiskini et al. [2012] compared the effects of iron supplements (ferric pyrophosphate, ferric pyrophosphate with emulsifiers, sodium iron EDTA, microencapsulated ferrous sulfate, and elemental iron) on the sensory and physical quality of iron-fortified GFB (40 mg/kg solid compound). They observed that the electrolytic iron was stable during thermal treatment, and thus its addition caused no adverse changes to GFB. In contrast, authors indicated the limitations of other iron supplements administered into GFB, in particular observed that the addition of ferric pyrophosphate and NaFeEDTA caused undesirable changes in bread, in particular darkening of crust and crumb and a metallic taste.

More often, however, the use of highly nutritious naturally gluten-free ingredients such as pseudocereals, minor cereals, legumes, and protein from various sources has been suggested as an important and dietary method for the improvement of the nutritional value of GFB. However, while the incorporation of such raw materials in gluten-free formulae may have advantages due to their high nutritional value, there are also disadvantages due to their technological limitations, which can change the appearance, colour, texture, aroma, and taste of GFB [Capriles et al., 2016]. Several excellent reviews summarized the nutritional aspects of fortified gluten-free products, including their glycaemic index and antioxidant capacity [Capriles \& Arêas, 2016; Taylor et al., 2016; Tsatsaragkou \& Mandala, 2016; Torres et al., 2017]. The recent application and properties of additional ingredients in GFB will be discussed in the following sections of this review.

\section{HOW TO IMPROVE GLUTEN-FREE BREAD?}

In the last few decades, a great deal of attention has been paid to the development of novel and healthier GFBs able to fulfil all quality requirements for bakery products [Capriles et al., 2016]. To this end, the special role of different protein sources has been strengthened and the use of alternative nutrient-dense raw materials and natural compounds has become increasingly popular.

\section{Proteins of animal and plant origin}

To build up a network similar to that formed by gluten in wheat bread production, the inclusion of other polymeric substances such as non-gluten proteins is a critical factor. Although proteins play a functional role in developing bread structure and texture, their inclusion in gluten-free formulae may also confer nutritional benefits to the final products [Ziobro et al., 2013a]. Different types of proteins of both plant (such as cereals, pseudocereals, and legumes) and animal origin (such as dairy proteins and egg albumins) have been used to produce protein-enriched GFBs [Crockett et al., 2011; Ziobro et al., 2013a; Aguilar et al., 2015; Collar et al., 2015].

Dairy ingredients such as caseinates, whey proteins, and skim milk powder were widely used in gluten-free breadmaking due to their functional properties, which are similar to these of gluten, and to their high nutritional value, which entails an increase in calcium and protein content and supply of essential amino acids [Stathopoulos, 2008; Nunes et al., 2009]. However, not all kinds of dairy proteins behave in the same way, as they possess different functionalities, which range from the ability of caseinates to stabilize the dough/batter, through the ability of isolated and concentrated whey proteins to form gels, to the high water-holding capacity of high-temperature skim milk powders [Nunes et al., 2009]. Thus, the addition of dairy proteins in GF bread formulae could have several effects on the overall quality of the intermediate and end products: (a) at the dough level, they increase water binding capacity and enhance the handling properties of dough/batter; (b) at the bread level, they increase loaf volume, improve texture, enhance crust colour and aroma, and reduce the staling rate [Houben et al., 2012]. Krupa-Kozak et al. [2013] evaluated the effects of the addition (12\% and 24\%) of four low lactose dairy proteins (calcium and sodium caseinate, dried whey protein isolate, and hydrolyzed whey proteins) on the behaviour of the dough and the quality properties of the resulting GFBs. They found that, although the GFBs exhibited higher protein content at all supplementation levels, breads prepared with the addition 
of $12 \%$ milk powders where more than 5 times richer in protein than the control one; in addition, their crumb softness, specific volume, crust darkening, and crumb lightness were observed to significantly increase. However, since many newly diagnosed patients with coeliac disease commonly report a secondary lactose deficiency caused by an inadequate secretion of lactase (which is normally produced by the intestinal villi), the use of high-lactose dairy ingredients in the development of gluten-free bakery products must be carefully considered.

Other kinds of proteins which have shown a great potential in gluten-free breadmaking are egg proteins. The addition of egg proteins as gluten replacers is due to their foaming ability, stabilizing effect, and emulsifying properties. However, due to their allergenic character, their use as food products ingredients should be limited or carefully considered [Phongthai et al., 2016].

Another way to include proteins in a GFB formulation is to use various types of legume grains. In fact, legumes offer a high nutritional value, suitable functional properties, and beneficial health effects. They are important sources of protein, whose content ranges from 18 to $25 \%$. Soybeans, however, are unique in that they contain about $35-43 \%$ protein [Tharanathan \& Mahadevamma, 2003]. Moreover, legume proteins, due to their high content of the essential amino acid - lysine which is often deficient in grain food, as well as a concomitant deficiency of methionine and cysteine, are nutritionally complementary to cereal proteins [Duranti, 2006]. Legumes are also good sources of minerals (such as calcium and iron), vitamins (especially B-group vitamins), and dietary fibre (both soluble and insoluble fractions). In addition, they are identified as low glycaemic index foods [Collar et al., 2014]. When incorporated into food matrices, legume proteins show a range of functional properties, which include foaming, emulsifying, and gelation capabilities as well as texture, water/oil binding capacity, and viscosity [Maninder et al., 2007]. In recent years, proteins from legume sources such as soybean, carob, pea, and lupine have been widely used in gluten-free breadmaking [Marco \& Rosell, 2008a; Crockett et al., 2011; Ziobro et al., 2016; Horstmann et al., 2017]. Soy proteins, which are usually added into the bread formulae either as soy protein isolates or high-protein soy flour, have for long been used to improve mechanical behaviour of doughs as well as textural properties, specific volume, and nutritional value of GFBs [Marco \& Rosell, 2008b]. However, soy flour incorporation may be curbed by its "beany" flavour. Shin et al. [2013] found that the pre-treatment of soy flour can improve not only the flavour but also technological parameters of GFBs. Carob, which is the fruit of the carob tree (Ceratonia siliqua L.) (also called locust bean) is cultivated throughout the Mediterranean region for its edible pods. Carob flour is rich in proteins, dietary fibre, micronutrients, and polyphenols [Turfani et al., 2017]. Moreover, it contains caroubin, a water-insoluble protein able to form wheat-like dough due to disulphide bonded high molecular weight proteins, which makes carob an interesting ingredient in gluten-free breadmaking [Smith et al., 2012]. In fact, it was observed that carob germ flour (7\%), when mixed with corn starch (93\%), HPMC (2\%) and water $(80 \%)$, was able to form viscoelastic dough similar to that of wheat, resulting in breads with both a higher specific volume and crumb softness [Smith et al., 2012]. Tsatsaragkou et al. [2014] used the Response Surface Methodology to optimise the levels of carob flour, resistant starch and water in rice-based GFBs. They reported that the use of $15 \%$ carob flour, $15 \%$ resistant starch, and $140 \%$ water resulted in GFBs rich in fibre $(6.10 \mathrm{~g} / 100 \mathrm{~g})$ and with softer crumb and improved porosity values. However, Miñarro et al. [2012] in their attempt to substitute soya protein with other legume proteins such as pea isolates, chickpea and carob germ flour, obtained opposite results. These authors found that, in spite of good rheological properties, the breads obtained with carob germ flour showed the lowest specific volume, the darkest crumb, and the highest values of hardness during 5 days of storage. On the contrary, the best overall behaviour (higher specific volume and softer crumb during storage) was observed in the breads produced with the addition of chickpea flour, probably due to the good emulsifying stability index of its proteins. Significant improvement in both the technological and the nutritional quality of GFB achieved via incorporation of chickpea flour has been recently reported also by other authors [Ouazib et al., 2016; Santos et al., 2018].

\section{Pseudocereals}

The rekindled interest in some under-utilized and naturally gluten-free plant species such as buckwheat, amaranth and quinoa derives from their excellent nutritional value. In fact, in addition to a superior protein profile, they have high contents of resistant starch, dietary fibre, and micronutrients, such as vitamins, minerals, and phenols. Although the number of gluten-free bakery products made of all three pseudocereals has increased significantly, buckwheat flour remains the most studied ingredient in the development of GFBs. On the contrary, only a few attempts have been made to include quinoa into GFB formulations [Capriles \& Arêas, 2014].

Buckwheat belongs to the family Poligonaceae and genus Fagopyrum, which consists of about 15 species cultivated around the world. However, among them, only two species are utilized for food consumption: Fagopyrum esculentum and Fagopyrum tataricum, which are also known as common and tartary buckwheat, respectively. The nutritional value of buckwheat flour is highly connected with its protein composition. In fact, contrarily to the true cereals, where the main proteins are glutelin and prolamins, buckwheat proteins are composed mainly of the water-soluble globulins and albumins, which contain high levels of the essential amino acids lysine and arginine, resulting in a well-balanced amino acids composition. Due to that, despite a protein content close to that measured in common cereal grains (12\%), buckwheat protein has a high biological value [Alvarez-Jubete et al., 2010a,b; Giménez-Bastida et al., 2017; Tömösközi \& Langó, 2017]. Buckwheat is also a source of minor components such as minerals (potassium, calcium, copper, zinc, and manganese), vitamins (B-group and E), and phenolic compounds (hyperin, quercitrin, and quercetin). In particular, among pseudocereals, it is unique in containing the flavonol glycoside-rutin with recognized anti-inflammatory and antioxidant properties [Zhang et al., 2012; Wronkowska et al., 2016; Tömösközi \& Langó, 2017]. Lukšič et al. [2016], evalu- 
ating the impact of sourdough fermentation and thermal processes on the conversion of rutin to quercetin in bread made of common and tartary buckwheat, observed that the combined effects of sourdough fermentation and baking process only preserve quercetin, but not rutin, in tartary buckwheat breads. In turn, Torbica et al. [2010] found that the incorporation of different levels (up to $30 \%$ ) of both husked and unhusked buckwheat flours in rice-based GFBs made the addition of hydrocolloids not necessary for a good development of the dough structure, without detrimental effects on the sensory bread acceptance (except for high levels of unhusked buckwheat flour). They also reported that the addition of increasing amounts of buckwheat flour reduced the starch retrogradation degree of the tested samples, leading to a final product with improved anti-staling properties. Other study assessed the effect of a dehulled and puffed buckwheat flour application at $40 \%$ substitution level on the nutritional value of two commercial GFB mixtures [Mariotti et al., 2013]. Authors indicated that the inclusion of $40 \%$ dehulled buckwheat flour improved the leavening properties of the commercial GF mixtures. Moreover, the presence of a small amount of puffed buckwheat flour and HPMC limited the diffusion/ loss of water from the bread crumb and the interactions between starch and protein macromolecules, resulting in a softer GFB crumb and reduced staling kinetics during storage. Krupa-Kozak et al. [2011b] reported that the addition of different levels of buckwheat flour (from 10\% to 40\%) improved the technological and nutritional quality of breads made with corn and potato starch. In particular, they observed that the increasing levels of buckwheat supplementation resulted in a proportional enrichment of the final products with both proteins and microelements ( $\mathrm{Cu}$ and $\mathrm{Mg}$ ). Turkut et al. [2016] demonstrated that, in gluten-free formulations based on rice flour, potato starch and buckwheat flour, the replacement of buckwheat with increasing levels of quinoa flour (up to $50 \%$ ) can improve the bread sensory flavour and the overall liking, without detrimental effects on baking loss, specific volume and protein content, when levels of substitution were up to $25 \%$.

In the last few years, apart from buckwheat flour, special emphasis has also been put on the inclusion of nutritious amaranth and quinoa flours into gluten-free formulations. Amaranth belongs to the family Amaranthaceae and genus Amaranthus, which consists of about 60 different species. Among them, A. caudatus, A. cruentus, and A. hypochondriacus are the three main species commonly used for food consumption. Quinoa belongs to the family Chenopodiaceae and genus Chenopodium, in which, due to the presence of bitter tasting saponins whose contents can range from 0.03 to $2.05 \%$, it is possible to identify sweet and bitter varieties [Schoenlechner et al., 2008]. Amaranth and quinoa have higher protein contents (14-15\% and $13-14 \%$, respectively) compared to the true cereal grains. Furthermore, their amino acid compositions, with high levels of the essential amino acids lysine and methionine, are well-balanced and comparable (or even higher) to those of whole egg and casein, respectively [Schoenlechner et al., 2008]. In addition to protein, amaranth and quinoa are rich in many nutrients, such as dietary fibre, folate, riboflavin, ascorbic acid, tocopherol, and phenolic compounds. More- over, they have a total mineral content (calcium, magnesium, iron, potassium, and zinc) approximately 2 times higher than that of true cereals [Schoenlechner et al., 2008]. The use of both amaranth and quinoa in GFB production has been recently investigated by Machado Alencar et al. [2015]. These authors reported that the supplementation of a starch-rich base formulation, containing cassava, potato, sour tapioca, and rice flour with amaranth, quinoa (20\%) and different sweeteners (stevia, sucralose, and sucralose/acesulfame-K blend) led to breads with higher contents of protein, lipids and ash, without detrimental effects on the specific volume, firmness, and water activity. In particular, the best results were obtained in the experimental sample prepared with quinoa and stevia, which showed the highest specific volume and the lowest crumb firmness values.

\section{Minor cereals: Sorghum and Teff}

Sorghum (Sorghum vulgare) is a member of the grass family, which is more closely related to corn and wild rice than to wheat, rye and barley. For this reason, it is often used as a safe ingredient in gluten-free breadmaking [Schober et al., 2007; Vallons et al., 2010; Marston et al., 2016]. In addition, the white and bland-taste flours obtained from the so-called food-grade sorghum lines, do not impart unusual colours or strong flavours to food products and, therefore, may be preferred over maize flour [Taylor et al., 2006]. The major constituent of sorghum is starch, which constitutes about $72 \%$ of the whole grain. However, although sorghum has a similar chemical composition to that of maize, its starch tends to have a slow digesting profile and a higher gelatinization temperature, which could lead to an inadequate gelatinization during baking. Its protein content, ranging between $8.6 \%$ and $15.6 \%$, is similar to that found in other cereal grains. Furthermore, sorghum proteins have poor nutritional quality (low lysine content) as well as poor functionality during processing. In fact, the prolamins of sorghum are located in protein bodies that have a relatively hydrophobic surface [Awika, 2017]. However, due to the large amount of bioactive compounds present in sorghum grain, it can be considered as a potential source of nutraceuticals [Taylor et al., 2006]. In particular, sorghum contains phenolic acids and flavonoids, which are responsible for the different colour of sorghum grains. However, certain cultivars have higher contents of condensed tannins (proanthocyanidins) and, therefore, exhibit bitter taste [Awika, 2017]. Thus, the use of sorghum as the main ingredient in gluten-free breadmaking can have advantages but also limitations. Specifically, some physicochemical properties of sorghum flour negatively affect the breadmaking performance. In fact, during milling, the horny part of the endosperm forms coarse grits, which contribute to a coarse and sandy mouthfeel. The further milling of such grits into fine flour results in a high amount of damaged starch. Furthermore, when heated, sorghum proteins can form aggregates that, interfering with the starch gel, lead to breads with flat top and big holes in the crumb [Onyango et al., 2011b]. As reported by Schober et al. [2005], the use of different varieties of sorghum can also affect the quality characteristics of the resulting breads. When comparing the breadmaking performance of 10 sorghum flours (70\%) blended with $30 \%$ 
corn starch, these authors observed significant differences in crumb hardness and crumb grain properties. They suggested that starch damage, which is influenced by kernel hardness, might have a key role in these differences. Moreover, despite no significant differences in the specific volume of the different breads, these authors concluded that larger bread volumes could be reached when corn starch is added to the sorghum flour. The importance of starch damage as well as sorghum flour composition and particles size on bread performance was also observed by Trappey et al. [2015]. In particular, they found that flour with a lower content of fibre and a smaller particle size enabled producing breads with more acceptable volume, crumb structure, colour, and texture. In their attempts to improve the quality of sorghum GFB, other authors adopted various promising approaches, including: (a) high-pressure processing [Vallons et al., 2010] and heat treatment of sorghum flour [Marston et al., 2016]; (b) the use of native and pregelatinised starch, and enzymes [Onyango et al., 2010; 2011a, b]; and (c) the use of sourdough fermentation [Schober et al., 2007].

Teff is an ancient cereal originating from Ethiopia where it is used to make traditional food preparations that range from typical baked goods, such as injera (leavened flatbread) and kitta (unleavened bread) through typical local spirits and opaque beer, such as tella, to porridge and soups [Bultosa \& Taylor, 2002; Zhu, 2018]. Teff belongs to the family Poaceae and genus Eragrostis, which consists of over 350 species, of which Eragrostis tef is the only cultivated species. The renewed interest in the use of teff flour as a valuable ingredient in food processing is mainly due to its desirable nutritional properties and the absence of gluten. In terms of chemical composition, $73 \%$ of the total carbohydrates is composed of starch, which shows a low degree of retrogradation [Bultosa \& Taylor, 2002]. The protein content of teff (8.7-11\%) is close to that found in other cereals, such as wheat, maize, and barley but, unlike them, it has a well-balanced amino acid composition. Moreover, the essential amino acid profile of teff, except for its relatively lower lysine and isoleucine contents, is comparable to that of egg protein [Gebremariam et al., 2014]. Since teff flour is usually obtained by grinding the whole tiny seeds, it has a high content of dietary fibre $(9.8 \%$ dry basis) [Zhu, 2018]. Teff contains also considerable levels of vitamins and, compared to other cereals such as wheat, barley and sorghum, it is a good source of iron, calcium, and zinc. Furthermore, in addition to a lower lipid content (2-3\%) [Schober et al., 2007], teff flour is rich in unsaturated fatty acids (72.46\%), including oleic acid (32.41\%) and linoleic acid $(23.83 \%)$ [Gebremariam et al., 2014]. Although there has been a lot of research dealing with the physical, sensory, and nutritional performance of wheat breads supplemented with teff flours, only few studies have been published regarding its potential use as novel and nutritional ingredient in gluten-free breadmaking [Campo et al., 2016; Marti et al., 2017].

\section{Dietary fibre}

GFB is often characterised by a low content of dietary fibre, ranging from $1.2 \%$ to $7.2 \%$ in commercial GFBs [Thompson et al., 2005; Segura \& Rosell, 2011]. The refining process results in a decrease in fibre content as during this process the outer layer of grains containing most of the fibre is removed, and the starchy inner part is left. Dietary fibres consist of non-digestible carbohydrates and lignin that are intrinsic and intact in plants and should be resistant to the enzymes of the early-sections of the digestive tract and fermented in the colon by gut microbiota [Anderson et al., 2009]. The daily intake of dietary fibre should range from 25 to $38 \mathrm{~g}$ [Drabińska et al., 2018a]. The Joint WHO/FAO Expert Consultation on Diet, Nutrition and the Prevention of Chronic Diseases [Nishida et al., 2004] stated that an adequate amount of fibre in the diet confers several health benefits including body mass management, as well as reduction of hypertension and risk of type 2 diabetes and cardiovascular diseases [Anderson et al., 2009].

Inulin-type fructans (ITF) are commonly consumed soluble dietary fibres, which are more fermentable and viscous than the insoluble fibres [Slavin, 2013]. The structure of ITF, characterized by $\beta$-configuration, determines their ability to reach the colon in the intact form and their prebiotic properties [Drabińska et al., 2018a]. ITF have not only nutritional quality, but can also affect the technological parameters of food products, which was widely studied in gluten-free breadmaking. Inulin can affect the quality of bread at every step of the production process. Hager et al. [2011] demonstrated that inulin influenced the moisture content of gluten-free batter. The inulin microcrystals led to the formation of a gel structure entrapping large volumes of water, which resulted in a less elastic and more viscous dough with a creamy texture. After baking, inulin-enriched GFB had a darker crust, but also harder crumb, and an increased rate of staling in comparison with the control bread without inulin [Slavin, 2013]. Similar findings were reported by Rodriguez et al. [2015], who analysed the addition of inulin to GFB fortified with bovine plasma proteins. Inulin-enriched GFB had smoother crust, increased loaf volume and reduced hardness, because of a decreased thickness of the walls surrounding the small air cells. The authors showed that inulin reduced the moisture loss and, simultaneously, delayed the staling of breads [Hager et al., 2011], which in another study was found the reason behind the faster aging and staling of stored bread [Capriles \& Arêas, 2013]. Korus et al. [2006] found that 5\% enrichment of GFB with inulin resulted in an increased volume and decreased crumb hardness. However, the authors reported that too high addition of inulin may result in GFB with wrinkling crust and reduced cohesiveness and springiness of the crumb [Korus et al., 2006].

ITF is a group of compounds varying in the length of the chemical chain, i.e. in the degree of their polymerization (DP), and consequently having different properties. Long-chain inulin significantly affects rheological and viscoelastic properties of gluten-free dough, causing a decrease in consistency and paste viscosity and an increase in the compliance values and gelatinization temperatures [Juszczak et al., 2012]. On the other hand, short-chain inulin was found to increase bread volume, improve crumb texture (uniform and medium size porosity), and decrease the staling rate [Ziobro et al., 2013b]. To obtain breads with various properties, a mixture of short- and long-chain ITF was also examined. Capriles \& Arêas [2013] found that irrespectively of the amount of mixed 
TABLE 2. By-products used in gluten-free breadmaking.

\begin{tabular}{|c|c|c|c|}
\hline By products & Effect on gluten-free dough & Effect on gluten-free bread & References \\
\hline Blackcurrant seeds & $\begin{array}{l}\text { At the highest level (15\%): Modified } \\
\text { viscoelastic properties, } \\
\text { Decreased values of consistency } \\
\text { coefficients and flow indices }\end{array}$ & $\begin{array}{c}\text { Decreases loaf volume, } \\
\text { Slight increase in crumb hardness, } \\
\text { gumminess and chewiness, } \\
\text { Increased levels of proteins, dietary } \\
\text { fibre, and polyphenols }\end{array}$ & [Korus et al., 2012] \\
\hline Strawberry seeds & $\begin{array}{l}\text { At the highest level (15\%): Modified } \\
\text { viscoelastic properties, } \\
\text { Decreased values of consistency } \\
\text { coefficients and flow indices }\end{array}$ & $\begin{array}{c}\text { Increased loaf volume } \\
\text { Decreased crumb hardness, } \\
\text { gumminess and chewiness } \\
\text { Increased levels of proteins, dietary } \\
\text { fibre, and polyphenols }\end{array}$ & [Korus et al., 2012] \\
\hline Orange pomace & $\begin{array}{l}\text { Increased robustness of the batter, } \\
\text { Decreased occurrence of starch gelatinization }\end{array}$ & $\begin{array}{c}\text { Increased specific volume, } \\
\text { Detrimental effect on crumb structure } \\
\text { (dense and compact loaf), } \\
\text { Decreased crumb hardness during } \\
\text { storage (at lower level of addition), } \\
\text { Increased levels of dietary fibre }\end{array}$ & [O'Shea et al., 2013] \\
\hline
\end{tabular}

fructans added, the obtained breads were characterised by an enlarged volume and specific volume, probably due to the increased $\mathrm{CO}_{2}$ retention capacity. Moreover, ITFs positively affected the crust colour of GFB, probably due to enhanced formation of brown nitrogenous polymers and melanoidins via Maillard reaction during baking. The authors also confirmed the improvement in the sensory quality of GFB fortified with ITFs. Irrespective of the amount of ITF added, the enriched breads received higher scores in terms of their appearance, colour, texture, and taste. Moreover, the fortified breads had a lower glycaemic index and glycaemic load and higher contents of dietary fibre [Capriles \& Arêas, 2013]. The sensory acceptance was also found to be dependent on DP [Morais et al., 2014]. GFB fortified with short-chain fructooligosaccharides received the highest scores for crust colour, porosity, and texture as well as for taste and flavour.

\section{By-products}

Recently, about one third of the fruit and vegetable, including peels, skins, outer leaves and seeds, is wasted during preparation and processing, which poses a huge problem for both the environment and the food industry. However, many of these by-products can be used as additives to gluten-free food products, thus finding a second life (Table 2). Fruit and vegetable by-products were found to be good sources of bioactive compounds, such as carotenoids, polyphenols, glucosinolates and vitamins, as well as dietary fibre [Domínguez-Perles et al., 2010; O'Shea et al., 2012; Radočaj et al., 2014; Majzoobi et al., 2016; Drabińska et al., 2018b]. For that reason, nowadays, an increasing number of research focuses on the evaluation of the nutritional quality and further application of by- and waste products as low-cost sources of nutrients and functional ingredients.

Defatted strawberry and blackcurrant seeds have been used as additional sources of dietary fibre, protein, and polyphenols in GFB [Korus et al., 2012]. The authors found that the addition of fruit seed modified the viscoelastic properties of gluten-free batter and decreased values of consistency coefficients and flow indices. Moreover, hardness of GFB was reduced by the addition of fruit by-products, especially strawberry seeds. The incorporation of defatted strawberry seed increased the loaf volume as compared to GFB enriched with blackcurrant seed and control bread, which was explained by a higher content of sugars which enhance the ability of yeast to produce $\mathrm{CO}_{2}$ [Korus et al., 2012].

Orange pomace, being a good source of dietary fibre (up to $40 \% \mathrm{DM}$ ) and bioactive compounds (minerals, vitamins), is another by-product that has been studied in GFB development [O'Shea et al., 2013, 2015a,b; Talens et al., 2017]. The incorporation of orange pomace into gluten-free batter improved the robustness and decreased starch gelatinisation [O'Shea et al., 2013]. Furthermore, the obtained GFB enriched in orange pomace had a higher content of fibre (by 4\%) [O'Shea et al., 2015b]. In turn, Talens et al. [2017] showed that an attractive colour, flavour and texture of gluten-free muffins were obtained by the incorporation of a microwave-dried orange by-product to the batter.

The recent and on-going studies demonstrated that the use of by-products in the gluten-free food industry affords the possibility of improving the quality of many products. By-products are unused sources of dietary fibre, vitamins, minerals, and bioactive compounds, which can be used to increase the quality of gluten-free foodstuff which is usually poor. However, during the optimization of a novel gluten-free product, the pre-processing step should be considered as well.

\section{CONCLUSIONS}

The presence of gluten is considered fundamental for successful breadmaking. However, the elimination of gluten in cereal-based products has a detrimental effect on the breadmaking process and raises technological challenges in making good quality leavened bread. On the basis of the recent findings summarized in this review, it may be concluded that only the use of a combination of different ingredients and additives could result in GFBs with pleasant quality features that, in some cases, may be compared to those of the gluten-containing breads. In particular, the partial replacement of the conventional starchy ingredients with alternative nutrient-dense minor cereals, pseudocereals, and legumes allowed achieving promising results. The incorporation of low-cost sources of nutrients, such as different kinds of by- and waste 
products, has also been suggested as an interesting approach to improve the quality of GFB.

However, despite the considerable advances made in this field, the nutritional quality of gluten-free products still remains a critical issue. Since low levels of protein, fibre, and essential nutrients, as well as high contents of fat and sugar are too often observed in GFB, further research aimed at exploring new strategies to overcome this major problem is needed.

\section{CONFLICTS OF INTEREST}

The authors declare that there is no conflict of interest regarding the publication of this paper.

\section{FUNDING STATEMENT}

Supported by the grant of KNOW Consortium "Healthy Animal - Safe Food", MS\&HE Decision No. 05-1/ KNOW2/2015.

\section{REFERENCES}

1. Aguilar, N., Albanell, E., Miñarro, B., Capellas, M. (2015). Chickpea and tiger nut flours as alternatives to emulsifier and shortening in gluten-free bread. LWT - Food Science and Technology, 62(1), 225-232.

2. Akhtar, S., Anjum, F.M., Anjum, M.A. (2011). Micronutrient fortification of wheat flour: Recent development and strategies. Food Research International, 44(3), 652-659.

3. Alvarez-Jubete, L., Arendt, E.K., Gallagher, E. (2010a). Nutritive value of pseudocereals and their increasing use as functional gluten-free ingredients. Trends in Food Science \& Technology, 21 (2), 106-113.

4. Alvarez-Jubete, L., Auty, M., Arendt, E., Gallagher, E. (2010b). Baking properties and microstructure of pseudocereal flours in gluten-free bread formulations. European Food Research and Technology, 230(6), 437-445.

5. Anderson, J.W., Baird, P., Davis, R.H., Jr., Ferreri, S., Knudtson, M., Koraym, A., Waters, V., Williams, C.L. (2009). Health benefits of dietary fiber. Nutrition Reviews, 67(4), 188-205.

6. Awika, J.M. (2017). Sorghum: Its Unique Nutritional and HealthPromoting Attributes. In J.N.R. Taylor, J.M. Awika (Eds.), Gluten-Free Ancient Grains: Cereals, Pseudocereals, and Legumes: Sustainable, Nutritious, and Health-Promoting Foods for the 21st Century. Woodhead Publishing Limited, Cambridge, pp. 21-54.

7. Bathrellou, E., Kontogianni, M.D., Panagiotakos, D.B. (2018). Celiac disease and non-celiac gluten or wheat sensitivity and health in later life: A review. Maturitas, 112, 29-33.

8. Bultosa, G., Taylor, J.R.N. (2002). Paste and gel properties and in vitro digestibility of teff [Eragrostis tef (Zucc.) Trotter] starch. Starch/Stärke, 56, 20-28.

9. Campo, E., del Arco, L., Urtasun, L., Oria, R., Ferrer-Mairal, A. (2016). Impact of sourdough on sensory properties and consumers' preference of gluten-free breads enriched with teff flour. Journal of Cereal Science, 67, 75-82.

10. Cappa, C., Lucisano, M., Mariotti, M. (2013). Influence of Psyllium, sugar beet fibre and water on gluten-free dough properties and bread quality. Carbohydrate Polymers, 98(2), 1657-1666.
11. Capriles, V.D., Arêas, J.A.G. (2013). Effects of prebiotic inulintype fructans on structure, quality, sensory acceptance and glycemic response of gluten-free breads. Food \& Function, 4(1), 104-110.

12. Capriles, V.D., Arêas, J.A.G. (2014). Novel approaches in gluten-free breadmaking: Interface between food science, nutrition, and health. Comprehensive Reviews in Food Science and Food Safety, 13(5), 871-890.

13. Capriles, V.D., Arêas, J.A.G. (2016). Approaches to reduce the glycemic response of gluten-free products: In vivo and in vitro studies. Food \& Function, 7(3), 1266-1272.

14. Capriles, V.D., dos Santos, F.G., Arêas, J.A.G. (2016). Gluten-free breadmaking: Improving nutritional and bioactive compounds. Journal of Cereal Science, 67, 83-91.

15. Collar, C., Conte, P., Fadda, C., Piga, A. (2015). Gluten-free dough-making of specialty breads: Significance of blended starches, flours and additives on dough behaviour. Food Science \& Technology International, 21 (7), 523-536.

16. Collar, C., Jiménez, T., Conte, P., Fadda, C. (2014). Impact of ancient cereals, pseudocereals and legumes on starch hydrolysis and antiradical activity of technologically viable blended breads. Carbohydrate Polymers, 113, 149-158.

17. Conte, P., Del Caro, A., Balestra, F., Piga, A., Fadda, C. (2018). Bee pollen as a functional ingredient in gluten-free bread: A physical-chemical, technological and sensory approach. LWT - Food Science and Technology, 90, 1-7.

18. Conte, P., Fadda, C., Piga, A., Collar, C. (2016). Techno-functional and nutritional performance of commercial breads available in Europe. Food Science \& Technology International, 22(7), 621-633.

19. Cornejo, F., Rosell, C.M. (2015). Physicochemical properties of long rice grain varieties in relation to gluten free bread quality. LWT - Food Science and Technology, 62 (2), 1203-1210.

20. Crockett, R., Ie, P., Vodovotz, I. (2011). Effects of soy protein isolate and egg white solids on the physicochemical properties of gluten-free breads. Food Chemistry, 129(1), 84-91.

21. de la Hera, E., Martinez, M., Oliete, B., Gómez, M. (2013). Influence of flour particle size on quality of gluten-free rice cakes. Food and Bioprocess Technology, 6(9), 2280-2288.

22. de la Hera, E., Rosell, C.M., Gomez, M. (2014). Effect of water content and flour particle size on gluten-free bread quality and digestibility. Food Chemistry, 151, 526-531.

23. Demirkesen, I., Kelkar, S., Campanella, O.H., Sumnu, G., Sahin, S., Okos, M. (2014). Characterization of structure of gluten-free breads by using X-ray microtomography. Food Hydrocolloids, 36, $37-44$.

24. Department of Health. (1998). Report on health and social subjects. No. 49. Nutrition and bone health with particular reference to calcium and vitamin D. London: HMSO.

25. Domínguez-Perles, R., Martínez-Ballesta, M.C., Carvajal, M., García-Viguera, C., Moreno, D.A. (2010). Broccoli-derived byproducts-A promising source of bioactive ingredients. Journal of Food Science, 75(4), C383-C392.

26. Drabińska, N., Ciska, E., Szmatowicz, B., Krupa-Kozak, U. (2018b). Broccoli by-products improve the nutraceutical potential of gluten-free mini sponge cakes. Food Chemistry, 267, 170-177.

27. Drabińska, N., Rosell, C.M., Krupa-Kozak, U. (2018a). Inulintype fructans application in gluten-free products: Functionality 
and health benefits. In J.-M. Mérillon \& K. G. Ramawat (Eds.), Bioactive Molecules in Food. Springer International Publishing, Cham, pp. 1-40.

28. Drabińska, N., Zieliński, H., Krupa-Kozak, U. (2016). Technological benefits of inulin-type fructans application in gluten-free products - A review. Trends in Food Science \& Technology, 56, 149-157.

29. Duranti, M. (2006). Grain legume proteins and nutraceutical properties. Fitoterapia, 77(2), 67-82.

30. Elgeti, D., Nordlohne, S. D., Föste, M., Besl, M., Linden, M. H., Heinz, V., Jeklea, M., Becker, T. (2014). Volume and texture improvement of gluten-free bread using quinoa white flour. Journal of Cereal Science, 59(1), 41-47.

31. Fadda, C., Sanguinetti, A.M., Del Caro, A., Collar, C., Piga, A. (2014). Bread staling: Updating the view. Comprehensive Reviews in Food Science and Food Safety, 13(4), 473-492.

32. Gallagher, E., Gormley, T.R., Arendt, E.K. (2003). Crust and crumb characteristics of gluten free breads. Journal of Food Engineering, 56(2-3), 153-161.

33. Gallagher, E., Gormley, T.R., Arendt, E.K. (2004). Recent advances in the formulation of gluten-free cereal-based products. Trends in Food Science \& Technology, 15(3-4), 143-152.

34. Gebremariam, M.M., Zarnkow, M., Becker, T. (2014). Teff (Eragrostis tef) as a raw material for malting, brewing and manufacturing of gluten-free foods and beverages: A review. Journal of Food Science and Technology, 51 (11), 2881-2895.

35. Giménez-Bastida, J.A., Zielinski, H., Piskula, M.K., Zielinska, D., Szawara-Nowak, D. (2017). Buckwheat bioactive compounds, their derived phenolic metabolites and their health benefits. Molecular Nutrition \& Food Research, 61, art. no. 1600475.

36. Gómez, M., Sciarini, L.S. (2015). Gluten-free bakery products and pasta. In Arranz E., Fernandex Banares F., Rosell C.M. (Eds.) Advances in the Understanding of Gluten Related Pathology and the Evolution of Gluten-Free Foods. OmniaScience, Barcelona, pp. 565-604.

37. Gray, J.A., Bemiller, J.N. (2003). Bread staling: Molecular basis and control. Comprehensive Reviews in Food Science and Food Safety, 2(1), 1-21.

38. Gujral, H.S., Haros, M., Rosell, C.M. (2003). Starch hydrolyzing enzymes for retarding the staling of rice bread. Cereal Chemistry, 80(6), 750-754.

39. Hager, A.S., Ryan, L.A.M., Schwab, C., Gänzle, M.G., O'Doherty, J.V., Arendt, E.K. (2011). Influence of the soluble fibres inulin and oat $\beta$-glucan on quality of dough and bread. European Food Research and Technology, 232 (3), 405-413.

40. Hager, A.S., Wolter, A., Czerny, M., Bez, J., Zannini, E., Arendt, E.K., Czerny, M. (2012). Investigation of product quality, sensory profile and ultrastructure of breads made from a range of commercial gluten-free flours compared to their wheat counterparts. European Food Research and Technology, 235(2), 333-344.

41. Haghighat-Kharazi, S., Milani, J.M., Kasaai, M.R., Khajeh, K. (2018). Microencapsulation of -amylase in beeswax and its application in gluten-free bread as an anti-staling agent. $L W T$ Food Science and Technology, 92, 73-79.

42. Haines, M.L., Anderson, R.P., Gibson, P.R. (2008). Systematic review: The evidence base for long-term management of coeliac disease. Alimentary Pharmacology \& Therapeutics, 28(9), 1042-1066.

43. Hallert, C., Grant, C., Grehn, S., Grännö, C., Hultén, S., Midhagen, G., Ström, M., Svensson, H., Valdimarsson, T. (2002).
Evidence of poor vitamin status in coeliac patients on a gluten-free diet for 10 years. Alimentary Pharmacology \& Therapeutics, 16(7), 1333-1339.

44. Hoefler, A.C. (2004). Hydrocolloids, Eagan Press Handobook, St. Minnesota, USA: Paul.

45. Horstmann, S.W., Axel, C., Arendt, E.K. (2018). Water absorption as a prediction tool for the application of hydrocolloids in potato starch-based bread. Food Hydrocolloids, 81, 129-138.

46. Horstmann, S.W., Foschia, M., Arendt, E. K. (2017). Correlation analysis of protein quality characteristics with gluten-free bread properties. Food \& Function, 8(7), 2465-2474.

47. Houben, A., Höchstötter, A., Becker, T. (2012). Possibilities to increase the quality in gluten-free bread production: An overview. European Food Research and Technology, 235(2), 195-208. https://doi.org/10.1007/s00217-012-1720-0

48. Jnawali, P., Kumar, V., Tanwar, B. (2016). Celiac disease: Overview and considerations for development of gluten-free foods. Food Science and Human Wellness, 5(4), 169-176.

49. Juszczak, L., Witczak, T., Ziobro, R., Korus, J., Cieślik, E., Witczak, M. (2012). Effect of inulin on rheological and thermal properties of gluten-free dough. Carbohydrate Polymers, 90(1), 353-360.

50. Kadan, R.S., Robinson, M.G., Thibodeaux, D.P., Pepperman, A.B. (2001). Texture and other physicochemical properties of whole rice bread. Journal of Food Science, 66(7), 940-944.

51. Kiskini, A., Kapsokefalou, M., Yanniotis, S., Mandala, I. (2012). Effect of iron fortification on physical and sensory quality of gluten-free bread. Food and Bioprocess Technology, 5(1), 385-390.

52. Korus, J., Grzelak, K., Achremowicz, K., Sabat, R. (2006). Influence of prebiotic additions on the quality of gluten-free bread and on the content of inulin and fructooligosaccharides. Food Science \& Technology International, 12 (6), 489-495.

53. Korus, J., Juszczak, L., Ziobro, R., Witczak, M., Grzelak, K., Sójka, M. (2012). Defatted strawberry and blackcurrant seeds as functional ingredients of gluten-free bread. Journal of Texture Studies, 43(1), 29-39.

54. Korus, J., Witczak, M., Ziobro, R., Juszczak, L. (2009). The impact of resistant starch on characteristics of gluten-free dough and bread. Food Hydrocolloids, 23(3), 988-995.

55. Krupa-Kozak, U. (2014). Pathologic bone alterations in celiac disease: etiology, epidemiology, and treatment. Nutrition, 30(1), $16-24$.

56. Krupa-Kozak, U., Altamirano-Fortoul, R., Wronkowska, M., Rosell, C.M. (2012). Breadmaking performance and technological characteristic of gluten-free bread with inulin supplemented with calcium salts. European Food Research and Technology, 23(3), 545-554.

57. Krupa-Kozak, U., Bączek, N., Rosell, C.M. (2013). Application of dairy proteins as technological and nutritional improvers of calcium-supplemented gluten-free bread. Nutrients, 5(11), 4503-4520.

58. Krupa-Kozak, U., Troszyńska, A., Bączek, N., Soral-Śmietana, M. (2011a). Effect of organic calcium supplements on the technological characteristic and sensory properties of gluten-free bread. European Food Research and Technology, 232(3), 497-508.

59. Krupa-Kozak, U., Wronkowska, M., Soral-Śmietana, M. (2011b). Effect of buckwheat flour on microelements and proteins contents in gluten-free bread. Czech Journal of Food Sciences, 29(2), 103-108. 
60. Lazaridou, A., Duta, D., Papageorgiou, M., Belc, N., Biliaderis, C.G. (2007). Effects of hydrocolloids on dough rheology and bread quality parameters in gluten-free formulations. Journal of Food Engineering, 79(3), 1033-1047.

61. Lukšič, L., Bonafaccia, G., Timoracka, M., Vollmannova, A., Trček, J., Nyambe, T.K., Melini, V., Acquistucci, R., Germa, M., Kreft, I. (2016). Rutin and quercetin transformation during preparation of buckwheat sourdough bread. Journal of Cereal Science, 69, 71-76.

62. Machado Alencar, N.M., Steel, C.J., Alvim, I.D., de Morais, E.C., Andre Bolini, H.M. (2015). Addition of quinoa and amaranth flour in gluten-free breads: Temporal profile and instrumental analysis. LWT - Food Science and Technology, 62 (2), 1011-1018.

63. Majzoobi, M., Poor, Z.V., Jamalian, J., Farahnaky, A. (2016). Improvement of the quality of gluten-free sponge cake using different levels and particle sizes of carrot pomace powder. International Journal of Food Science \& Technology, 51 (6), 1369-1377.

64. Mancebo, C.M., San Miguel, M.Á., Martínez, M.M., Gómez, M. (2015). Optimisation of rheological properties of gluten-free doughs with HPMC, psyllium and different levels of water. Journal of Cereal Science, 61, 8-15.

65. Maninder, K., Sandhu, K.S., Singh, N. (2007). Comparative study of the functional, thermal and pasting properties of flours from different field pea (Pisum sativum L.) and pigeon pea (Cajanus cajan L.) cultivars. Food Chemistry, 104(1), 259-267.

66. Marco, C., Rosell, C.M. (2008a). Breadmaking performance of protein enriched, gluten-free breads. European Food Research and Technology, 227(4), 1205-1213.

67. Marco, C., Rosell, C.M. (2008b). Functional and rheological properties of protein enriched gluten-free composite flours. Journal of Food Engineering, 88(1), 94-103.

68. Mariotti, M., Pagani, M.A., Lucisano, M. (2013). The role of buckwheat and HPMC on the breadmaking properties of some commercial gluten-free bread mixtures. Food Hydrocolloids, 30(1), 393-400.

69. Marston, K., Khouryieh, H., Aramouni, F. (2016). Effect of heat treatment of sorghum flour on the functional properties of gluten-free bread and cake. LWT - Food Science and Technology, 65, 637-644.

70. Marti, A., Marengo, M., Bonomi, F., Casiraghi, M.C., Franzetti, L., Pagani, M.A., Iametti, S. (2017). Molecular features of fermented teff flour relate to its suitability for the production of enriched gluten-free bread. LWT - Food Science and Technology, 78, 296-302. https://doi.org/10.1016/j.lwt.2016.12.042

71. Martin, J., Geisel, T., Maresch, C., Krieger, K., Stein, J. (2013). Inadequate nutrient intake in patients with celiac disease: results from a German dietary survey. Digestion, 87(4), 240-246. https:// doi.org/10.1159/000348850

72. Martínez, M.M., Gómez, M. (2017). Rheological and microstructural evolution of the most common gluten-free flours and starches during bread fermentation and baking. Journal of Food Engineering, 197, 78-86.

73. Matos, M.E., \& Rosell, C.M. (2015). Understanding gluten-free dough for reaching breads with physical quality and nutritional balance. Journal of the Science of Food and Agriculture, 95(4), 653-661.

74. Matos, M.E., Rosell, C.M. (2013). Quality indicators of ricebased gluten-free bread-like products: Relationships between dough rheology and quality characteristics. Food and Bioprocess Technology, 6(9), 2331-2341.
75. Meyer, D., Stavropolous, S., Diamond, B., Shane, E., Green, P.H.R. (2001). Osteoporosis in a north American adult population with celiac disease. The American Journal of Gastroenterology, 96(1), 112-119.

76. Miñarro, B., Albanell, E., Aguilar, N., Guamis, B., Capellas, M. (2012). Effect of legume flours on baking characteristics of gluten-free bread. Journal of Cereal Science, 56(2), 476-481.

77. Mir, S.A., Shah, M.A., Naik, H.R., Zargar, I.A. (2016). Influence of hydrocolloids on dough handling and technological properties of gluten-free breads. Trends in Food Science \& Technology, 51, 49-57.

78. Mohammadi, M., Sadeghnia, N., Azizi, M.H., Neyestani, T.R., Mortazavian, A.M. (2014). Development of gluten-free flat bread using hydrocolloids: Xanthan and CMC. Journal of Industrial and Engineering Chemistry, 20(4), 1812-1818.

79. Morais, E.C., Cruz, A.G., Faria, J.A.F., Bolini, H.M.A. (2014). Prebiotic gluten-free bread: Sensory profiling and drivers of liking. LWT - Food Science and Technology, 55(1), 248-254.

80. Morreale, F., Angelino, D., Pellegrini, N. (2018a). Designing a score-based method for the evaluation of the nutritional quality of the gluten-free bakery products and their gluten-containing counterparts. Plant Foods for Human Nutrition (Dordrecht, Netherlands), 73(2), 154-159.

81. Morreale, F., Garzón, R., Rosell, C.M. (2018b). Understanding the role of hydrocolloids viscosity and hydration in developing gluten-free bread. A study with hydroxypropylmethylcellulose. Food Hydrocolloids, 77, 629-635.

82. Naji-Tabasi, S., Mohebbi, M. (2015). Evaluation of cress seed gum and xanthan gum effect on macrostructure properties of gluten-free bread by image processing. Journal of Food Measurement and Characterization, 9(1), 110-119.

83. Nishida, C., Uauy, R., Kumanyika, S., Shetty, P. (2004). The joint WHO/FAO expert consultation on diet, nutrition and the prevention of chronic diseases: Process, product and policy implications. Public Health Nutrition, 7(1A, 1a), 245-250.

84. Nunes, M.H.B., Ryan, L.A.M., Arendt, E.K. (2009). Effect of low lactose dairy powder addition on the properties of gluten-free batters and bread quality. European Food Research and Technology, 229(1), 31-41.

85. O'Shea, N., Arendt, E.K., Gallagher, E. (2012). Dietary fibre and phytochemical characteristics of fruit and vegetable byproducts and their recent applications as novel ingredients in food products. Innovative Food Science \& Emerging Technologies, 16, 1-10.

86. O'Shea, N., Doran, L., Auty, M., Arendt, E., Gallagher, E. (2013). The rheology, microstructure and sensory characteristics of a gluten-free bread formulation enhanced with orange pomace. Food \& Function, 4(12), 1856-1863.

87. O'Shea, N., Ktenioudaki, A., Smyth, T.P., McLoughlin, P., Doran, L., Auty, M.A.E., Gallagher, E. (2015a). Physicochemical assessment of two fruit by-products as functional ingredients: Apple and orange pomace. Journal of Food Engineering, 153, 89-95.

88. O'Shea, N., Rößle, C., Arendt, E., Gallagher, E. (2015b). Modelling the effects of orange pomace using response surface design for gluten-free bread baking. Food Chemistry, 166, 223-230.

89. Onyango, C., Mutungi, C., Unbehend, G., Lindhauer, M.G. (2010). Rheological and baking characteristics of batter and bread prepared from pregelatinised cassava starch and sorghum and modified using microbial transglutaminase. Journal of Food Engineering, 97(4), 465-470. 
90. Onyango, C., Mutungi, C., Unbehend, G., Lindhauer, M.G. (2011a). Modification of gluten-free sorghum batter and bread using maize, potato, cassava or rice starch. $L W T$ - Food Science and Technology, 44(3), 681-686.

91. Onyango, C., Mutungi, C., Unbehend, G., Lindhauer, M.G. (2011b). Rheological and textural properties of sorghum-base formulations modified with variable amounts of native or pregelatinised cassava starch. LWT - Food Science and Technology, 44(3), 687-693.

92. Ouazib, M., Garzon, R., Zaidi, F., Rosell, C.M. (2016). Germinated, toasted and cooked chickpea as ingredients for breadmaking. Journal of Food Science and Technology, 53(6), 2664-2672 .

93. Peña-Bautista, R.J., Hernandez-Espinosa, N., Jones, J.M., Guzmán, C., Braun, H.J. (2017). Wheat-based foods: Their global and regional importance in the food supply, nutrition and health. Cereal Foods World, 62(5), 231-249.

94. Penagini, F., Dilillo, D., Meneghin, F., Mameli, C., Fabiano, V., Zuccotti, G.V. (2013). Gluten-free diet in children: An approach to a nutritionally adequate and balanced diet. Nutrients, 5(11), 4553-4565.

95. Phongthai, S., D’Amico, S., Schoenlechner, R., Rawdkuen, S. (2016). Comparative study of rice bran protein concentrate and egg albumin on gluten-free bread properties. Journal of $\mathrm{Ce}$ real Science, 72, 38-45.

96. Pietzak, M. (2012). Celiac disease, wheat allergy, and gluten sensitivity: When gluten free is not a fad. Journal of Parenteral and Enteral Nutrition, 36(1, Suppl), 68S-75S.

97. Primo-Martín, C., van de Pijpekamp, A., van Vliet, T., de Jongh, H.H.J., Plijter, J.J., Hamerab, R.J. (2006). The role of the gluten network in the crispness of bread crust. Journal of Cereal Science, 43(3), 342-352.

98. Pruska-Kędzior, A., Kędzior, Z., Gorący, M., Pietrowska, K., Przybylska, A., Spychalska, K. (2008). Comparison of rheological, fermentative and baking properties of gluten-free dough formulations. European Food Research and Technology, 227(5), $1523-1536$.

99. Radočaj, O., Dimić, E., Tsao, R. (2014). Effects of hemp (Cannabis sativa $\mathrm{L}$.) seed oil press-cake and decaffeinated green tea leaves (Camellia sinensis) on functional characteristics of gluten-free crackers. Journal of Food Science, 79(3), C318-C325.

100. Rinaldi, M., Paciulli, M., Caligiani, A., Scazzina, F., Chiavaro, E. (2017). Sourdough fermentation and chestnut flour in gluten-free bread: A shelf-life evaluation. Food Chemistry, 224, 144-152.

101. Rodriguez Furlán, L.T., Pérez Padilla, A., Campderrós, M.E. (2015). Improvement of gluten-free bread properties by the incorporation of bovine plasma proteins and different saccharides into the matrix. Food Chemistry, 170, 257-264.

102. Ronda, F., Caballero, P.A., Quilez, J., Roos, Y.H. (2011). Staling of frozen partly and fully baked breads. Study of the combined effect of amylopectin recrystallization and water content on bread firmness. Journal of Cereal Science, 53, 97-103.

103. Ronda, F., Perez-Quirce, S., Lazaridou, A., Biliaderis, C.G. (2015). Effect of barley and oat $\beta$-glucan concentrates on gluten-free rice-based doughs and bread characteristics. Food Hydrocolloids, 48, 197-207. https://doi.org/10.1016/j.foodhyd.2015.02.031

104. Ronda, F., Perez-Quirce, S., Villanueva, M. (2017). Rheological Properties of Gluten-Free Bread Doughs: Relationship With
Bread Quality. In J. Ahmed (Ed.), Advances in Food Rheology and Its Applications. Woodhead Publishing Series, pp. 297-334.

105. Rosell, C.M., Marco, C. (2008). Rice. In E.K. Arendt, F. Dal Bello (Eds.), Gluten-Free Cereal Products and Beverages. . Elsevier/Academic Press, London, pp. 81-111.

106. Różyło, R., Dziki, D., Gawlik-Dziki, U., Cacak-Pietrzak, G., Miś, A., Rudy, S. (2015). Physical properties of gluten-free bread caused by water addition. International Agrophysics, 29(3), 353-364.

107. Santos, F.G., Fratelli, C., Muniz, G., Capriles, V.D. (2018). Mixture design applied to the development of chickpea-based gluten-free bread with attractive technological, sensory, and nutritional quality. Journal of Food Science, 83(1), 188-197.

108. Saturni, L., Ferretti, G., Bacchetti, T. (2010). The gluten-free diet: safety and nutritional quality. Nutrients, 2(1), 16-34.

109. Scanlon, M.G., Zghal, M.C. (2001). Bread properties and crumb structure. Food Research International, 34(10), 841-864.

110. Scherf, K.A., Koehler P., Wieser, H. (2016). Gluten and wheat sensitivities - An overview. Journal of Cereal Science 67, 2-11.

111. Schober, T.J., Bean, S.R., Boyle, D.L. (2007). Gluten-free sorghum bread improved by sourdough fermentation: Biochemical, rheological, and microstructural background. Journal of Agricultural and Food Chemistry, 55(13), 5137-5146.

112. Schober, T.J., Bean, S.R., Boyle, D.L., Park, S.H. (2008). Improved viscoelastic zein-starch doughs for leavened gluten-free breads: Their rheology and microstructure. Journal of Cereal Science, 48(3), 755-767.

113. Schober, T.J., Messerschmidt, M., Bean, S.R., Park, S.-H., Arendt, E.K. (2005). Gluten-free bread from sorghum: quality differences among hybrids. Cereal Chemistry, 82(4), 394-404.

114. Schoenlechner, R., Siebenhandl, S., Berghofer, E. (2008). Pseudocereals. In E.K. Arendt, F. Dal Bello (Eds.), Gluten-free cereal products and beverages. Elsevier/Academic Press, London, pp. 149-190.

115. Sciarini, L.S., Ribotta, P.D., León, A.E., Pérez, G.T. (2010). Influence of gluten-free flours and their mixtures on batter properties and bread quality. Food and Bioprocess Technology, 3, 577-585.

116. Sdepanian, V.L., de Miranda Carvalho, C.N., de Morais, M.B., Colugnati, F.A.B., Fagundes-Neto, U. (2003). Bone mineral density of the lumbar spine in children and adolescents with celiac disease on a gluten-free diet in São Paulo, Brazil. Journal of Pediatric Gastroenterology and Nutrition, 37(5), 571-576.

117. Segura, M.E., Rosell, C.M. (2011). Chemical composition and starch digestibility of different gluten-free breads. Plant Foods for Human Nutrition (Dordrecht, Netherlands), 66(3), 224-230.

118. Shin, D.-J., Kim, W., Kim, Y. (2013). Physicochemical and sensory properties of soy bread made with germinated, steamed, and roasted soy flour. Food Chemistry, 141(1), 517-523.

119. Simić, M., Žilić, S., Šimuruna, O., Filipčev, B., Škrobot, D., Vančetović J. (2018). Effects of anthocyanin-rich popping maize flour on the phenolic profile and the antioxidant capacity of mix-bread and its physical and sensory properties. Polish Journal of Food and Nutrition Sciences, 68(4), 299-308.

120. Singh, H., MacRitchie, F. (2001). Application of polymer science to properties of gluten. Journal of Cereal Science, 33(3), 231-243.

121. Slavin, J. (2013). Fiber and prebiotics: Mechanisms and health benefits. Nutrients, 5(4), 1417-1435. 
122. Smith, B.M., Bean, S.R., Herald, T.J., Aramouni, F.M. (2012). Effect of HPMC on the quality of wheat-free bread made from carob germ flour-starch mixtures. Journal of Food Science, 77(6), C684-C689.

123. Stathopoulos, C.E. (2008). Dairy based ingredients. In E.K. Arendt, F. Dal Bello (Eds.), Gluten-free cereal products and beverages, Elsevier/Academic Press, London, pp. 217-236.

124. Talens, C., Álvarez-Sabatel, S., Rios, Y., Rodríguez, R. (2017). Effect of a new microwave-dried orange fibre ingredient vs. a commercial citrus fibre on texture and sensory properties of gluten-free muffins. Innovative Food Science \& Emerging Technologies, 44, 83-88.

125. Taylor, J.N.R., Schober, T.J., Bean, S.R. (2006). Novel food and non-food uses for sorghum and millets. Journal of Cereal Science, 44(3), 252-271.

126. Taylor, J.R.N., Taylor, J., Campanella, O.H., Hamaker, B.R. (2016). Functionality of the storage proteins in gluten-free cereals and pseudocereals in dough systems. Journal of Cereal Science, 67, 22-34.

127. Tharanathan, R.N., Mahadevamma, S. (2003). Grain legumes - a boon to human nutrition. Trends in Food Science \& Technology, 14(12), 507-518.

128. Theethira, T.G., Dennis, M., Leffler, D.A. (2014). Nutritional consequences of celiac disease and the gluten-free diet. Expert Review of Gastroenterology \& Hepatology, 8(2), 123-129.

129. Thompson, T. (1999). Thiamin, riboflavin, and niacin contents of the gluten-free diet: Is there cause for concern? Journal of the American Dietetic Association, 99(7), 858-862.

130. Thompson, T., Dennis, M., Higgins, L.A., Lee, A.R., Sharrett, M.K. (2005). Gluten-free diet survey: are Americans with coeliac disease consuming recommended amounts of fibre, iron, calcium and grain foods? Journal of Human Nutrition and Dietetics, 18(3), 163-169.

131. Tömösközi, S., Langó, B. (2017). Buckwheat: Its Unique Nutritional and Health-Promoting Attributes. In R.N. Taylor, J.M. Awika (Eds), Gluten-free Ancient Grains: Cereals, Pseudocereals, and Legumes: Sustainable, Nutritious, and HealthPromoting Foods for the 21st Century. Woodhead Publishing Limited, Cambridge, pp. 161-177.

132. Torbica, A., Hadnadev, M., Dapčević, T. (2010). Rheological, textural and sensory properties of gluten-free bread formulations based on rice and buckwheat flour. Food Hydrocolloids, 24(6-7), 626-632.

133. Torres, M., Arufe, S., Chenlo, F., Moreira, R. (2017). Coeliacs cannot live by gluten free bread alone - every once in a while they need antioxidants. International Journal of Food Science and Technology 52, 81-90.

134. Trappey, E.F., Khouryieh, H., Aramouni, F., Herald, T. (2015) Effect of sorghum flour composition and particle size on quality properties of gluten-free bread. Food Science \& Technology International, 21 (3), 188-202.

135. Tsatsaragkou K., Mandala, S.P. (2016). Structural role of fibre addition to increase knowledge of non-gluten bread. Journal of Cereal Science, 67, 58-67.

136. Tsatsaragkou, K., Gounaropoulos, G., Mandala, I. (2014). Development of gluten free bread containing carob flour and resistant starch. LWT - Food Science and Technology, 58(1), 124-129.
137. Turfani, V., Narducci, V., Durazzo, A., Galli, V., Carcea, M. (2017). Technological, nutritional and functional properties of wheat bread enriched with lentil or carob flours. $L W T$ - Food Science and Technology, 78, 361-366.

138. Turkut, G.M., Cakmak, H., Kumcuoglu, S., Tavman, S. (2016). Effect of quinoa flour on gluten-free bread batter rheology and bread quality. Journal of Cereal Science, 69, 174-181.

139. Vallons, K.J.R., Ryan, L.A.M., Koehler, P., Arendt, E.K. (2010). High pressure-treated sorghum flour as a functional ingredient in the production of sorghum bread. European Food Research and Technology, 231(5), 711-717.

140. Wandersleben, T., Morales, E., Burgos-Diaz, C., Barahona, T., Labra, E., Rubilar, M., Salvo-Garrido, H. (2018). Enhancement of functional and nutritional properties of bread using a mix of natural ingredients from novel varieties of flaxseed and lupine. LWT - Food Science and Technology, 91, 48-54.

141. Wang, S., Karrech, A., Regenauer-Lieb, K., Chakrabati-Bell, S. (2013). Digital bread crumb: Creation and application. Journal of Food Engineering, 116(4), 852-861.

142. Wierdsma, N.J., van Bokhorst-de van der Schueren, M.A., Berkenpas, M., Mulder, C.J., van Bodegraven, A.A. (2013). Vitamin and mineral deficiencies are highly prevalent in newly diagnosed celiac disease patients. Nutrients, 5(10), 3975-3992.

143. Witczak, M., Juszczak, L., Ziobro, R., Korus, J. (2012). Influence of modified starches on properties of gluten-free dough and bread. Part I: Rheological and thermal properties of glutenfree dough. Food Hydrocolloids, 28(2), 353-360.

144. Witczak, M., Ziobro, R., Juszczak, L., Korus, J. (2016). Starch and starch derivatives in gluten-free systems - A review. Journal of Cereal Science, 67, 46-57.

145. Wronkowska, M., Piskuła, M.K., Zieliński, H. (2016). Effect of roasting time of buckwheat groats on the formation of Maillard reaction products and antioxidant capacity. Food Chemistry, 196, 355-358.

146. Wronkowska, M., Troszyńska, A., Soral-Smietana, M., Wołejszo, A. (2008). Effects of buckwheat flour [Fagopyrum esculentum Moench] on the quality of gluten-free bread. Polish Journal of Food and Nutrition Sciences, 58, 211-216.

147. Yazynina, E., Johansson, M., Jagerstad, M., Jastrebova, J. (2008). Low folate content in gluten-free cereal products and their main ingredients. Food Chemistry, 111(1), 236-242.

148. Yousif, E.I., Gadallah, M.G.E., Sorour, A.M. (2012). Physicochemical and rheological properties of modified corn starches and its effect on noodle quality. Annals of Agricultural Sciences, 57, 19-27.

149. Zannini, E., Jones, J.M., Renzetti, S., Arendt, E.K. (2012). Functional replacements for gluten. Annual Review of Food Science and Technology, 3(1), 227-245.

150. Zhang, D., Mu, T., Sun, H. (2017). Comparative study of the effect of starches from five different sources on the rheological properties of gluten-free model doughs. Carbohydrate Polymers, 176, 345-355.

151. Zhang, Z-L., Zhou, M-L., Tang, Y., Li, F-L., Tang, Y-X., Shao, J. R., Xue, W-T., Wu, Y-M. (2012). Bioactive compounds in functional buckwheat food. Food Research International, 49, 389-395.

152. Zhu, F. (2018). Chemical composition and food uses of teff (Eragrostis tef). Food Chemistry, 239, 402-415. 
153. Ziobro, R., Juszczak, L., Witczak, M., Korus, J. (2016). Nongluten proteins as structure forming agents in gluten free bread. Journal of Food Science and Technology, 53(1), 571-580.

154. Ziobro, R., Korus, J., Juszczak, L., Witczak, T. (2013b). Influence of inulin on physical characteristics and staling rate of gluten-free bread. Journal of Food Engineering, 116(1), 21-27.
155. Ziobro, R., Witczak, T., Juszczak, L., Korus, J. (2013a). Supplementation of gluten-free bread with non-gluten proteins. Effect on dough rheological properties and bread characteristic. Food Hydrocolloids, 32(2), 213-220.

Submitted: 7 August 2018. Revised: 24 September 2018. Accepted: 17 October 2018. Published on-line: 3 December 2018. 
